\title{
Accuracy of Working Length Measurement by Raypex 6: Electronic Apex Locator versus Actual Measurements under Stereomicroscope
}

\begin{abstract}
SUMMARY
Background/Aim: This study aimed to evaluate the precision of the Raypex 6 apex locator in locating the apical constriction (AC) and major foramen (MF) during a root canal treatment compared with a microscopic evaluation. Another aim of the present study was to evaluate the accuracy of the Raypex 6 in the presence of different irrigating solutions ( $\mathrm{NaOCl}$, saline, EDTA, etidronic acid-HEBP). Material and Methods: One hundred and nine patients were included in this study and were randomly assigned into four groups according to the irrigation solution used; $\mathrm{NaOCl}$, EDTA, $H E B F$ and saline. Electronic $M F(E M F)$ and $A C$ (EAC) were measured by using Raypex 6. The teeth were extracted. The apical $3 \mathrm{~mm}$ of each canal was trimmed to expose the file tip. The samples were observed under a stereomicroscope, and the actual length of $M F$ (ALMF) and $A C$ (ALAC) were measured. The data were analyzed by using $x^{2}$ test, and significance was set at $P<0.05$. Results: The Raypex 6 was accurate $71.4 \%$ of the time to $\pm 0.5 \mathrm{~mm}$ and $93.3 \%$ of the time to $\pm 1 \mathrm{~mm}$ in determining the ALAC. While similar ALAC-EAC differences were observed in EDTA, $\mathrm{NaOCl}$, and saline groups $(p=0.230)$, the highest differences were seen in the HEBP group $(p=1.000)$. The precision of Raypex 6 in determining the working length measurement depends on the type of irrigation. All solutions allowed reliable detection of AC. However, HEBF significantly increased the risk of overpreparation. Conclusions: Raypex 6 can be recommended for clinical use and its accuracy is not affected by the type of irrigant when locating $M F$.

Key words: Raypex 6, Electronic Apex Locators, Working Length Measurement, Irrigation Solutions
\end{abstract}

Begum Unsal Peker, Yelda Erdem Hepsenoglu, Seyda Ersahan, Tan Firat Eyuboglu

Department of Endodontics, Faculty of Dentistry, Istanbul Medipol University, Istanbul, Turkey

\section{ORIGINAL PAPER (OP)}

Balk J Dent Med, 2022;15-21

\section{Introduction}

Root canal treatment (RCT) procedures should be confined within the root canal system ${ }^{1}$. The working length (WL) is defined as the distance between a coronal reference point and the point at which canal preparation and obturation should terminate ${ }^{2}$. Maintaining a correct working length (WL) during RCT is expected to positively influence the outcome of RCT. Commonly, the minor apical foramen or apical isthmus is considered the end of the area for canal preparation and filling. The minor apical foramen is the border line between the dental pulp and periodontal area, which is approximately
0.5-1 $\mathrm{mm}$ from the anatomic apex ${ }^{3}$. Failure to determine the root canal length can result in both over- and underestimation of the root canal length ${ }^{1,4}$.

Conventional measurement methods for working length determination are periapical radiographs and electronic apex locators (EALs). Apex locators have advantages over radiographic methods; electronic working length determination (EWL) with apex locators is easier, faster, and can be indefinitely repeated without exposure to radiation ${ }^{5}$. Moreover, modern apex locators can locate not only the apical foramen but also, in contrast to radiographic methods, the apical constriction ${ }^{6-9}$, which is an optimal endpoint for root canal preparation and filling ${ }^{1,10}$. The 
accuracy of apex locators is higher when compared with radiographic methods ${ }^{11-13}$. In addition, apex locators can diagnose perforations and root fractures ${ }^{2,14,15}$. The use of electronic devices to determine the WL was proposed first by Custer $^{16}$ in 1918, and the first EAL was developed following the investigation by Suzuki ${ }^{17}$ of the electrical resistance properties of oral tissues. The first generation of EALs was based on resistance, whereas the second generation worked on the basis of impedance. The main drawback of both these types, namely poor accuracy in the presence of electrolytes, was overcome by the introduction of later-generation EALs. Many studies have addressed the benefits and clinical performance of the many different models of EALs that have been developed in recent years ${ }^{8,9.18-20}$, among them the Raypex 6 (VDW, Munich, Germany). Raypex 6 (VDW, Munich, Germany) is the last member of the Raypex series and clinical performance was previously found to be successful with the evaluation of Raypex 4 and $5^{21-23}$. To our knowledge, no study has compared the accuracy of Raypex 6 in in vitro versus in vivo models (in a truly clinical condition).

The purpose of the study reported herein was to compare the accuracy of the Raypex 6 in establishing the WL under in clinical and in vitro conditions. Another aim of the present study was to evaluate the accuracy of the Raypex 6 in the presence of different irrigating solutions (NaOCL, saline, EDTA, and HEBF).

\section{Material and Methods}

This study was approved by the Ethics Review Committee for Research, Istanbul Medipol University, Istanbul, Turkey (\#059/2017). One hundred and nine patients who attended the Esenler Dental Clinic of the Istanbul Medipol University, with a need for extraction (e.g. caries or periodontal cause) were screened through periapical clinical and radiographic examination, by a single calibrated operator (BU). Following agreement to participate, the patients signed a statement of informed consent. The study was conducted in accordance with the guidelines of the World Medical Association Declaration of Helsinki, and the Institutional ethical committee. Inclusion criteria involved teeth with closed apex, one single-root, and an intact root. Exclusion criteria involved teeth with previous root canal treatment, root resorption, metallic restorations, fractures, or open apices.

All teeth were assigned randomly to one of four groups (each of which comprised of approximately 27 teeth); EDTA group (17\% EDTA), $\mathrm{NaOCl}$ group $(2.5 \% \mathrm{NaOCl}), \mathrm{HEBP}$ group $(9 \% \mathrm{HEBF})$ and saline group $(0.9 \% \mathrm{NaCl}$ isotonic sodium chloride). All clinical procedures and measurements were conducted by a single operator (BU). The teeth were isolated with a rubber dam under local anesthesia. Endodontic access was performed, and the coronal portion of each canal was flared with an SX Protaper file (Maillefer, Ballaigues, Switzerland). Each canal was then irrigated with the irrigation solution according to their assigned group. Excess fluid was removed from the pulp chamber with an air syringe, but no attempt was made to dry the canals. The Raypex 6 apex locator was used in accordance with the manufacturer's instructions. The clip was attached to the patient's lip, and the electrode was connected to a $15 \mathrm{~K}$-file with two silicone stoppers.

\section{Electronic Measurement/Working length determination using electronic apex locators}

The file was advanced within the root canal until the red ball began flashing, which indicates the major foramen (according to the manufacturer's instructions). The measurements were recorded as electronic major foramen (EMJ). The same file was again advanced within the root canal until the red ball, and then withdrawn until the LCD display showed a flashing $b^{2}{ }^{2}$. The third green line, just before the yellow lines, which corresponds to $0.5 \mathrm{~mm}$ short of the radiographic apex was determined for working length. The measurements were recorded as electronic apical constriction (EAC). Measurements were considered to be valid if they remained stable for at least 5 seconds.

\section{Actual Length Measurement/Actual Working length determinations under stereomicroscope}

The teeth were extracted and placed in 5.25\% $\mathrm{NaOCl}$ for $30 \mathrm{~min}$ to remove any residual organic tissue from the root and then stored in $0.9 \%$ saline solution. A size $15 \mathrm{~K}$-file was gently inserted into the canal until its tip was visible at the plane of the major foramen using a dental operating microscope at $10 \mathrm{x}$ magnification. The rubber stop was adjusted to the occlusal reference, and the distance from the stop to the tip of the instrument was measured by a magnifying glass (x10) and recorded in $\mathrm{mm}$ as the actual length major foramen (ALMF). To observe the apical constriction, a window of $3 \mathrm{~mm}$ in diameter was made in the apical portion of the root using a diamond bur until the root canal became visible under a stereomicroscope (SZ-TP, Olympus, Tokyo, Japan). Then the same file was advanced again in the root canal up to the major foramen. The apical parts of the specimens were photographed using a digital camera (Ken-AVision, Kansas City, MO, USA) after visualization using a stereomicroscope (Meiji Techno, Saitama, Japan) at $\times 10$ magnification (Figure 1a, 1b). On the images of each apex, two investigators determined the minor diameter (dentinocemental junction), the major foramen, and the file tip; the investigators worked together to reach a consensus. We then measured the distance from the minor diameter to the file tip with a computer-based system (Leica Interactive Measurements Dialog, Cambridge, England) (Figure 1c). The measurements were recorded as actual length apical constriction (ALAC). 


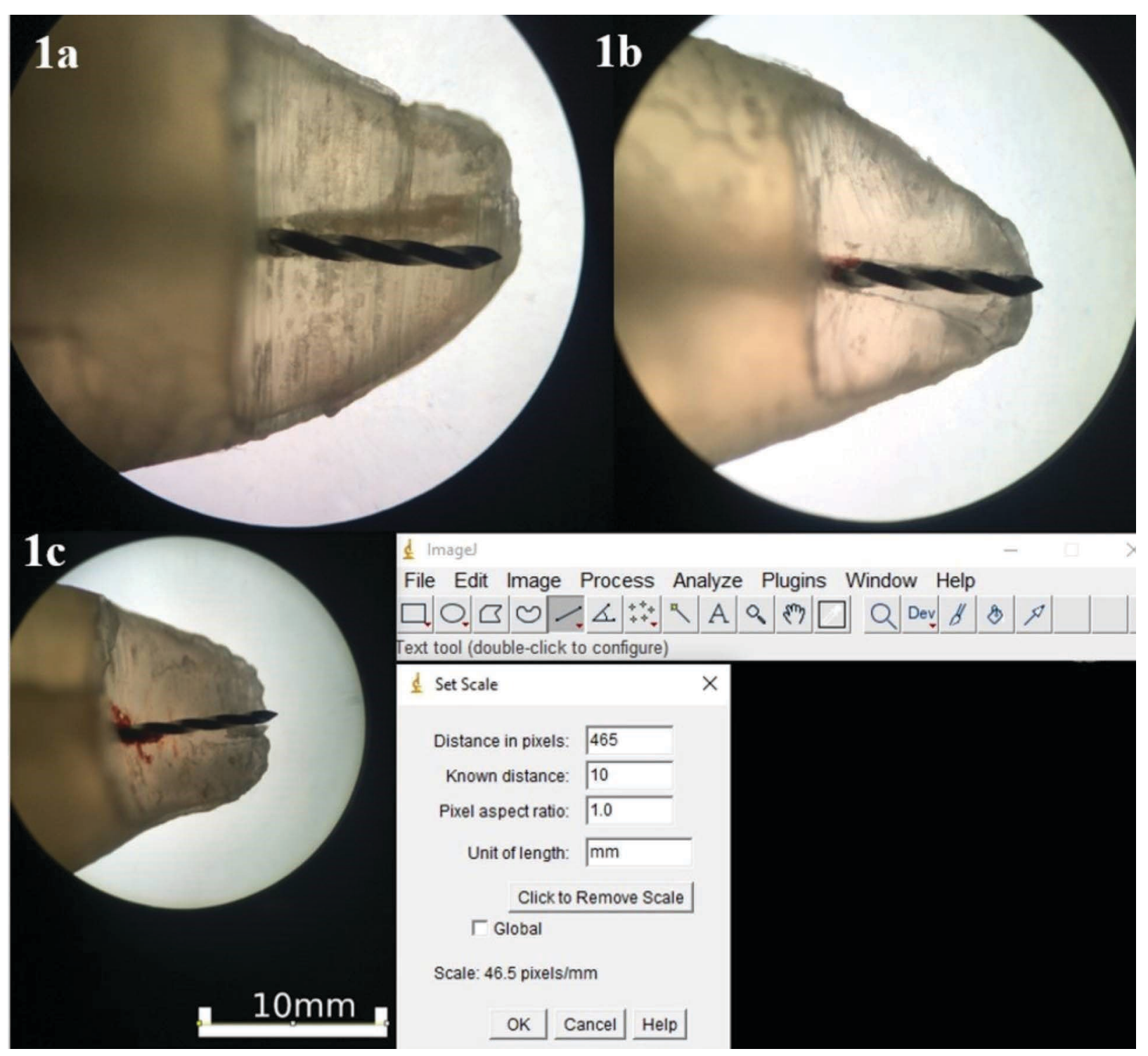

Figure 1. 1a) and 1b) Photographs of the specimens' apical parts under a stereomicroscope at $\times 10$ magnification; 1c) Measurement of the distance from the minor diameter to the file tip with a computer-based system

Differences between electronic and actual length measurements were calculated. Negative and positive values indicated measurements that respectively fell long and short of the AL, whilst 0.0 indicated coinciding measurements. The distance of the file tip from the AC/ MF were measured and recorded as being -1.0 or -0.5 $\mathrm{mm}$ from the $\mathrm{AC} / \mathrm{MF}$, respectively; at the $\mathrm{AC} / \mathrm{MF}$, or +0.5 $\mathrm{mm}$ or $+1.0 \mathrm{~mm}$ from the $\mathrm{AC} / \mathrm{MF}$, respectively. A minus symbol (-) indicated a file was through the AC/MF; A plus symbol $(+)$ indicated it was short of the AC/MF. Since the insertion length was already known, the actual length was determined by adding or subtracting the distance of the file tip from the $\mathrm{AC} / \mathrm{MF}$ to the insertion length.

\section{Statistical Analysis}

Power analysis was estimated using a GPower 3.1.9.4 program. The sample size was estimated as 27 teeth per group $(\alpha=0.05, \beta=0.05$, with a minimum value for clinical relevance of 0.5 ). KolmogorovSmirnov test was used to evaluate normality distribution. The dependent two-sample $T$ test was used. Statistical significance was set at $P<0.05$.

\section{Results}

Four teeth were excluded, because of broken tooth structure during extraction (one in the saline group and three in the HEBF group). Electronic measurements for apical constriction (EAC) were found to be significantly higher than the actual length measurements for apical constriction (ALAC) $(p=0.007$; Table 1). When the mean difference between the EAC and ALAC was evaluated, the 
saline group yielded the lowest mean value $(p=0.0000$; Table 2). Electronic measurements for major foramen (EMF) were found to be significantly higher than that of the actual length measurements for the major foramen (ALMF) ( $p=0.007$; Table 1). No significant difference was observed between the test groups according to the mean difference between the EMF and ALMF.

Table 1. Mean and standard deviations ( $\mathrm{mm}$ ) of differences between electronic measurements (EAC, EMF) and actual length (ALAC, ALMF)

\begin{tabular}{lcccc}
\hline Group & N & Average & S.D & $\boldsymbol{p}$ \\
\hline ALAC - EAC & 105 & -0.289 & 0.051 & \\
ALMF - EMF & 105 & -0.483 & 0.050 & $\mathbf{0 . 0 0 7 *}$ \\
\hline
\end{tabular}

ALAC: Actual apical constiriction; EAC: Electronic apical constriction; ALMF: Actual major foramen; EMF: Electronic major foramen; SD: Standard deviation
Table 2. Mean and standard deviations $(\mathrm{mm})$ of differences between electronic measurements (EAC) and actual length $(A L A C)$ with regard to irrigation solutions

\begin{tabular}{lllccc}
\hline & & N & Average & S.D & p \\
\hline \multirow{4}{*}{ ALAC-EAC } & NaOCI & 28 & -0.093 & 0.063 & \\
& EDTA & 29 & -0.305 & 0.106 & \\
& Saline & 25 & -0.060 & 0.086 & $0.000^{*}$ \\
& HEBP & 23 & -0.756 & 0.098 & \\
& NaOCI & 28 & -0.501 & 0.092 & \\
ALMF-EMF & EDTA & 29 & -0.349 & 0.084 & \multirow{2}{*}{0.259} \\
& Saline & 25 & -0.481 & 0.126 & \\
& HEBP & 23 & -0.633 & 0.089 & \\
\hline
\end{tabular}

ALAC: Actual apical constiriction; EAC: Electronic apical constriction; ALMF: Actual major foramen; EMF: Electronic major foramen S.D: Standard deviation

Table 3. Frequency and percentages of EAC measurements that prove short and long with respect to ALAC

\begin{tabular}{|c|c|c|c|c|c|c|c|}
\hline & Solutions & $\mathbf{n}$ & $\begin{array}{c}\text { Shorter than AL } \\
(1.0 \mathrm{~mm} \text { to } \\
0.5 \mathrm{~mm} ; \%)\end{array}$ & $\begin{array}{l}\text { Shorter than AL } \\
(0.5 \mathrm{~mm} \text { to } \\
0.0 \mathrm{~mm} ; \%)\end{array}$ & $\begin{array}{l}\text { Longer than } \mathrm{AL} \\
(0.0 \mathrm{~mm} \text { to - } \\
0.5 \mathrm{~mm} ; \%)\end{array}$ & $\begin{array}{l}\text { Longer than AL } \\
(-0.5 \mathrm{~mm} \text { to - } \\
1 \mathrm{~mm} ; \%)\end{array}$ & $\begin{array}{l}\text { Longer than AL } \\
(<-1 \mathrm{~mm} ; \%)\end{array}$ \\
\hline \multirow{4}{*}{ ALAC-EAC } & NaOCI & 28 & $3(10.7 \%)$ & $4(14.3 \%)$ & $21(75 \%)$ & $0(0 \%)$ & $0(0 \%)$ \\
\hline & EDTA & 29 & $0(0 \%)$ & $7(24.1 \%)$ & $17(58.7 \%)$ & $3(10.3 \%)$ & $2(6.9 \%)$ \\
\hline & Saline & 25 & $2(8 \%)$ & $5(20 \%)$ & $15(60 \%)$ & $3(12 \%)$ & $0(0 \%)$ \\
\hline & HEBP & 23 & $0(0 \%)$ & $1(4.3 \%)$ & $5(21.7 \%)$ & $12(52.2 \%)$ & $5(21.7 \%)$ \\
\hline \multirow{4}{*}{ ALMF-EMF } & NaOCI & 28 & $1(3.5 \%)$ & $1(3.5 \%)$ & $11(39.3 \%)$ & $12(42.9 \%)$ & $3(10.7 \%)$ \\
\hline & EDTA & 29 & $0(0 \%)$ & $6(20.7 \%)$ & $14(48.3 \%)$ & $7(24.1 \%)$ & $2(6.9 \%)$ \\
\hline & Saline & 25 & $2(8 \%)$ & $1(4 \%)$ & $7(28 \%)$ & $11(44 \%)$ & $4(16 \%)$ \\
\hline & НЕВР & 23 & $1(4.3 \%)$ & $1(4.3 \%)$ & $4(17.4 \%)$ & $15(65.3 \%)$ & $2(8.7 \%)$ \\
\hline
\end{tabular}

ALAC: Actual apical constiriction; EAC: Electronic apical constriction; ALMF: Actual major foramen; EMF: Electronic major foramen

Chi-Square $($ Crosstab) relationship test, Chi-Square Value $($ ALAC - EAC) $=49,141$; Chi-Square Value $($ ALMF - EMF $)=19,431$

Table 4. Frequency (\%) of measurements $\pm 0.5 \mathrm{~mm}$ of the $A C$

\begin{tabular}{llcc}
\hline & & $\begin{array}{c}\text { Shorter than ALAC } \\
(0.5 \mathrm{~mm} \text { to } 0.0 \mathrm{~mm} \%)\end{array}$ & $\begin{array}{c}\text { Longer than ALAC } \\
(0.0 \mathrm{~mm} \text { to }-0.5 \mathrm{~mm} ; \%)\end{array}$ \\
\hline \multirow{3}{*}{ ALAC-EAC } & NaOCI & $4(16 \%)$ & $21(84 \%)$ \\
& EDTA & $7(29.2 \%)$ & $17(70.8 \%)$ \\
& Saline & $5(25 \%)$ & $15(75 \%)$ \\
\hline
\end{tabular}

ALAC: Actual apical constriction ALAC: Actual apical constriction EAC: Electronic apical constriction

In determining the MF, the Raypex 6 was accurate $42.9 \%$ of the time to $\pm 0.5 \mathrm{~mm}$ and $89.5 \%$ of the time to $\pm 1 \mathrm{~mm}$. In determining the AC, the Raypex 6 was accurate $71.4 \%$ of the time to $\pm 0.5 \mathrm{~mm}$ and $93.3 \%$ of the time to \pm 1 $\mathrm{mm}$ (Table 3). Table 3 shows the percentages of \pm 0.5 and $\pm 1.0 \mathrm{~mm}$ measurements obtained. The AC $( \pm 0.5 \mathrm{~mm})$ was determined in $89.3 \%, 82.7 \%, 80 \%$ and $26.1 \%$ for $\mathrm{NaOCl}$, Saline, and EDTA (Table 3). Among the four irrigation solutions tested, EDTA, Saline, and $\mathrm{NaOCl}$ showed similar accuracy in detecting AC (Table 4).

\section{Discussion}

The aim of this study was to evaluate the precision of Raypex 6 apex locator in locating the apical 
constriction (AC) and major foramen (MF) during a root canal treatment compared with that of a microscopic evaluation. Accuracy of the Raypex 6 in the presence of different irrigating solutions was also evaluated. The accuracy of EALs with respect to the determination of the location of the apical constriction of the root canal or the major foramen has been examined by various methods that include radiographic method, cone bean computerized tomography, in vitro study models ${ }^{25-28}$. But the present study aimed to evaluate Raypex 6's accuracy under clinical conditions. First, WL determination by Raypex 6 in the mouth was determined and these values were measured again after tooth extraction under a stereomicroscope. Numerous studies have reported the accuracy of EALs in determining the location of the apical constriction of the root canal or the major foramen $8,9,18$. However, various authors have suggested that the precise location of the apical constriction cannot be determined ${ }^{29,30}$. Only histological evaluation can determine the precise location of this detected point in the root canal ${ }^{1}$. In the present study, the apical constriction was examined under stereomicroscope after extraction of the tooth. After extraction of the teeth, the distance between the instrument and the MF was measured after a longitudinal window had been performed on the apical portion of the root ${ }^{31-33}$. Therefore, clinical accuracy of Raypex 6 for AC evaluation is correctly correlated with the AC's accurate/actual position. MF was visualized after extraction of the tooth and this value was also correlated with clinical measurements.

The diameter of the $\mathrm{AC}$ and MF and the location of the MF are factors affecting the accuracy of EALs. In order to avoid the effects of these factors, only singlerooted premolars and incisors were included in the present study. Pre-flaring of root canals before measurement with EALs can increase the precision of WL determination ${ }^{34}$. Thus, the canals were pre-flared in the current study before WL measurement. In the present study, only teeth that were extracted from adult patients for periodontal or caries reasons were included. Different results might have been obtained for teeth with periradicular periodontitis, which in most cases presents with some degree of root resorption ${ }^{35}$. In addition, as explained in the Material and Methods section and as in other studies ${ }^{15,36}$, determination of the actual working length at the major foramen was made by observing the latter with a magnifying glass (x2.5). However, because identification of the apical constriction required higher magnification, a stereomicroscope (x10) was used. This methodological difference may have implied less precision in the measurements of the actual length to the major foramen. Diverse studies have usually considered the electronic measurements for the AC to be between the $0.5 \mathrm{~mm}$ mark $^{8,19,37,38}$, which is considered highly accurate ${ }^{39}$, and the $1 \mathrm{~mm}$ mark $^{14,22,40}$. One reason cited for accepting a 1.0 $\mathrm{mm}$ margin of error is the wide range seen in the shape of the apical third ${ }^{37,41}$. Thus, this variation is clinically acceptable ${ }^{37}$, because microscopic studies revealed that this landmark might be positioned within this range $e^{1,41}$.

In $71.4 \%$ (75 of the 105) and $93.3 \%$ (92 of the 105) of the measurements made, the margin of error in locating AC was \pm 0.5 and $\pm 1.0 \mathrm{~mm}$, respectively. These results are in line with previous findings ${ }^{25,26,42}$. A recent found that Raypex 6 was accurate $71.43 \%$ of the time to $\pm 0.5 \mathrm{~mm}$ in measuring $\mathrm{AC}$, nearly the same value with the present findings ${ }^{43}$. Moreover, no significant difference between Raypex 6 and Root ZX was found in another study ${ }^{25}$. These results indicate that the manufacturer enhanced the accuracy with Raypex 6 compared to Raypex 4. The manufacturer claims that Raypex 6 utilizes the latest multi-frequency apex locator technology and displays precise results. Among the four irrigation solutions tested, EDTA, Saline, and $\mathrm{NaOCl}$ showed similar and higher accuracy then with HEBP in detecting AC. This study showed a higher but not statistically significant rate of acceptable results $(100 \%, \pm 1 \mathrm{~mm})$ in the saline and $\mathrm{NaOCl}$ groups, which is in agreement with previous studies $^{25,42}$. In a recent study by Chukka $\mathrm{RR}^{44}, \mathrm{NaOCl}$ does not affect the WL determination of the EAL, similar with the present findings. HEBP's overestimated measurements in detecting $\mathrm{AC}$ can be explained by the fact that HEBP's ionization degree in liquids is lower than that of the other three solutions ${ }^{45}$. The lower ionization degree in HEBP explains its lower ion mobility and its weak conductiveness. It was stated that inconsistent or false measurements of EAL is due to the low conductivity of irrigants in root canals ${ }^{46}$. Since there has been no study studying the effect of HEBP on EAL's accuracy, the present results are the first documented. Although HEBP has some advantages like smear layer removal, not affecting the efficacy of $\mathrm{NaOCl}$ in clinical conditions, it can be cautiously used in AC determination.

In $42.9 \%$ (75 of the 105) and $89.5 \%$ (92 of the 105) of the measurements made, the margin of error in locating MF was \pm 0.5 and $\pm 1.0 \mathrm{~mm}$, respectively. Raypex 6 can cause over instrumentation in detecting MF regardless of the type of irrigant. These results are in contrast with the findings of Lucena et al. ${ }^{26}$. This difference can be due to the selection of the red ball as the reference point for MF in the present study, while Lucena et $a .^{26}$ used the third yellow bar as the reference point for MF. In addition to the reference point selection, the use of different types of irrigation solutions could have caused different results. Raypex 6 was found to be more reliable in detecting $\mathrm{AC}$ than detecting MF.

\section{Conclusions}

Under the conditions of this in vivo study, Raypex 6 was found to be more reliable in detecting $\mathrm{AC}$ 
than detecting MF. The 2 electronic measurements (EAC and EMF) give an overestimation of the actual working length (ALAC and ALMF). The present study revealed that electronic working length determination by Raypex 6 is not influenced by the presence of irrigation solutions, except for HEBP. Only HEBP have a statistically significant influence on the accuracy of the EAL in detection of apical constriction, but there was no statistically significant difference between all four irrigation solutions in detecting the major foramen.

\section{References}

1. Ricucci D, Langeland K. Apical limit of root-canal instrumentation and obturation, part 2. A histological study. Int Endod J, 1998;31:394-409.

2. Gordon MPJ, Chandler NP. Electronic apex locators. Int Endod J, 2004;37:425-437.

3. Mancini M, Felici R, Conte G, Costantini M, Cianconi L. Accuracy of three electronic apex locators in anterior and posterior teeth: an ex vivo study. J Endod, 2011;37:684-687.

4. Sjögren ULF, Hägglund B, Sundqvist G, Wing K. Factors affecting the long-term results of endodontic treatment. J Endod, 1990;16:498-504.

5. Pratten DH, McDonald NJ. Comparison of radiographic and electronic working lengths. J Endod, 1996;22:173-176.

6. Hoer D, Attin T. The accuracy of electronic working length determination. Int Endod J, 2004;37:125-131.

7. Plotino G, Grande NM, Brigante L, Lesti B, Somma F. Ex vivo accuracy of three electronic apex locators: Root ZX, Elements Diagnostic Unit and Apex Locator and ProPex. Int Endod J, 2006;39:408-414.

8. Tselnik M, Baumgartner JC, Marshall JG. An evaluation of root ZX and elements diagnostic apex locators. J Endod, 2005;31:507-509.

9. Wrbas KT, Ziegler AA, Altenburger MJ, Schirrmeister JF. In vivo comparison of working length determination with two electronic apex locators. Int Endod J, 2007;40:133-138.

10. Wu M-K, Wesselink PR, Walton RE. Apical terminus location of root canal treatment procedures. Oral Surgery, Oral Med Oral Pathol Oral Radiol Endod, 2000;89:99-103.

11. Kim E, Lee S-J. Electronic apex locator. Dent Clin North Am, 2004;48:35-54.

12. Krajczár K, Marada G, Gyulai G, Tóth V. Comparison of radiographic and electronical working length determination on palatal and mesio-buccal root canals of extracted upper molars. Oral Surgery, Oral Med Oral Pathol Oral Radiol Endod, 2008;106:e90-93.

13. Stein TJ, Corcoran JF. Radiographic "working length" revisited. Oral Surg Oral Med Oral Pathol, 1992;74:796-800.

14. Ebrahim AK, Wadachi R, Suda H. Accuracy of three different electronic apex locators in detecting simulated horizontal and vertical root fractures. Aust Endod J, 2006;32:64-69.

15. Azabal M, Garcia-Otero D, De la Macorra JC. Accuracy of the Justy II Apex locator in determining working length in simulated horizontal and vertical fractures. Int Endod J, 2004;37:174-177.
16. Custer LE. Exact Method of Locating the Apical Foramen. Dent Regist, 1918;72:420-425.

17. Suzuki K. Experimental study on iontophoresis. Jpn J Stomatol, 1942;16:411-429.

18. Welk AR, Baumgartner JC, Marshall JG. An in vivo comparison of two frequency-based electronic apex locators. J Endod, 2003;29:497-500.

19. Siu C, Marshall JG, Baumgartner JC. An in vivo comparison of the Root ZX II, the Apex NRG XFR, and Mini Apex Locator by using rotary nickel-titanium files. J Endod, 2009;35:962-965.

20. Stöber EK, Duran-Sindreu F, Mercadé M, Vera J, Bueno R, Roig M. An evaluation of root ZX and iPex apex locators: an in vivo study. J Endod, 2011;37:608-610.

21. Somma F, Castagnola R, Lajolo C, Paternò Holtzman L, Marigo L. In vivo accuracy of three electronic root canal length measurement devices: Dentaport ZX, Raypex 5 and ProPex II. Int Endod J, 2012;45:552-556.

22. ElAyouti A, Kimionis I, Chu A, Löst C. Determining the apical terminus of root-end resected teeth using three modern apex locators: a comparative ex vivo study. Int Endod J, 2005;38:827-833.

23. Stöber EK, de Ribot J, Mercadé M, Vera J, Bueno R, Roig $\mathrm{M}$, et al. Evaluation of the Raypex 5 and the Mini Apex Locator: an in vivo study. J Endod, 2011;37:1349-1352.

24. Milanovic I, Ivanovic V, Vujaskovic M, Ignjatovic S, Miletic V. Accuracy of three electronic apex locators in determining the apical foramen in multi-rooted teeth: Randomised clinical and laboratory study. Aust Endod J, 2015;41:35-43.

25. Aydin U, Karataslioglu E, Aksoy F, Yildirim C. In vitro evaluation of Root ZX and Raypex 6 in teeth with different apical diameters. J Conserv Dent JCD. 2015;18:66-69.

26. Lucena C, López JM, Martín JA, Robles V, GonzálezRodríguez MP. Accuracy of working length measurement: electronic apex locator versus cone-beam computed tomography. Int Endod J, 2014;47:246-256.

27. ElAyouti A, Weiger R, Löst C. The ability of root ZX apex locator to reduce the frequency of overestimated radiographic working length. J Endod, 2002;28:116-119.

28. Cianconi L, Angotti V, Felici R, Conte G, Mancini M. Accuracy of three electronic apex locators compared with digital radiography: an ex vivo study. J Endod, 2010;36:2003-2007.

29. Lee SJ, Nam KC, Kim Y-J, Kim DW. Clinical accuracy of a new apex locator with an automatic compensation circuit. J Endod, 2002;28:706-709.

30. Martínez-Lozano MA, Forner-Navarro L, Sánchez-Cortés J, Llena-Puy C. Methodological considerations in the determination of working length. Int Endod J, 2001;34:371-376.

31. Erdemir A, Eldeniz AU, Ari H, Belli S, Esener T. The influence of irrigating solutions on the accuracy of the electronic apex locator facility in the Tri Auto ZX handpiece. Int Endod J, 2007;40:391-397.

32. Moscoso S, Pineda K, Basilio J, Alvarado C, Roig M, Duran-Sindreu F. Evaluation of Dentaport ZX and Raypex 6 electronic apex locators: an in vivo study. Med Oral Patol Oral Cir Bucal, 2014;19:e202-205.

33. Duran Sindreu F, Stöber E, Mercadé M, Vera J, Garcia M, Bueno R, et al. Comparison of in vivo and in vitro readings when testing the accuracy of the Root ZX apex locator. J Endod, 2012;38:236-239. 
34. de Camargo ÉJ, Zapata RO, Medeiros PL, Bramante CM, Bernardineli N, Garcia RB, et al. Influence of preflaring on the accuracy of length determination with four electronic apex locators. J Endod, 2009;35:1300-1302.

35. Malueg LA, Wilcox LR, Johnson W. Examination of external apical root resorption with scanning electron microscopy. Oral Surgery, Oral Med Oral Pathol Oral Radiol Endod, 1996;82:89-93.

36. Jenkins JA, Walker III WA, Schindler WG, Flores CM. An in vitro evaluation of the accuracy of the root $\mathrm{ZX}$ in the presence of various irrigants. J Endod, 2001;27:209-211.

37. Shabahang S, Goon WWY, Gluskin AH. An in vivo evaluation of Root ZX electronic apex locator. J Endod, 1996;22:616-618.

38. Pascon EA, Marrelli M, Congi O, Ciancio R, Miceli F, Versiani MA. An in vivo comparison of working length determination of two frequency-based electronic apex locators. Int Endod J, 2009;42:1026-1031.

39. Ounsi HF, Naaman A. In vitro evaluation of the reliability of the Root ZX electronic apex locator. Int Endod J, 1999;32:120-123.

40. Goldberg F, De Silvio AC, Manfré S, Nastri N. In vitro measurement accuracy of an electronic apex locator in teeth with simulated apical root resorption. J Endod, 2002;28:461-463.

41. Dummer PMH, Mcgınn JH, Rees DG. The position and topography of the apical canal constriction and apical foramen. Int Endod J, 1984;17:192-198.

42. Yolagiden M, Ersahan S, Suyun G, Bilgeç E, Aydin C. Comparison of Four Electronic Apex Locators in Detecting Working Length: An Ex Vivo Study. J Contemp Dent Pract, 2018;19:1427-1433.
43. Mahmoud O, Awad Abdelmagied MH, Dandashi AH, Jasim BN, Tawfik Kayali HA, Al Shehadat S. Comparative Evaluation of Accuracy of Different Apex Locators: Propex IQ, Raypex 6, Root ZX, and Apex ID with CBCT and Periapical Radiograph-In Vitro Study. Int J Dent, 2021;2021:5563426.

44. Chukka RR, Bellam MD, Marukala NR, Dinapadu S, Konda NK, Nagilla J. Efficiency of an integrated apex locator in determining working length in various irrigating solutions: An in vivo study. J Pharm Bioallied Sci, 2020;12:S410-414.

45. Brown TL, LeMay Jr HE, Bursten BE, Murphy CJ. Chemistry: The central science. J Chem Educ, 1997;74:378-379.

46. Venturi M, Breschi L. A comparison between two electronic apex locators: an in vivo investigation. Int Endod J, 2005;38:36-45

Conflict of Interests: Nothing to declare.

Financial Disclosure Statement: Nothing to declare.

Human Rights Statement: All the procedures on humans were conducted in accordance with the Helsinki Declaration of 1975, as revised 2000. Consent was obtained from the patient/s and approved for the current study by national ethical committee.

Animal Rights Statement: None required.

Received on April 2, 2021.

Revised on Jun 12, 2021.

Accepted on September 24, 2021.

\section{Correspondence}

Yelda Erdem Hepşenoğlu

Faculty of Dentistry, Department of Endodontics

Istanbul Medipol University, Istanbul, Turkey

e-mail: yelda_erdem89@hotmail.com 